Abstracta Iranica Iranica

Revue bibliographique pour le domaine irano-aryen

Volume 34-35-36 | 2017

Comptes rendus des publications de 2011-2013

\title{
Cristelle Baskins. The Bride of Trébizond: Turks and Turkmens on a Florentine Wedding Chest, circa 1460
}

\section{Matthieu Chochoy}

\section{(2) OpenEdition}

1 Journals

\section{Édition électronique}

URL : http://journals.openedition.org/abstractairanica/42195

DOI : 10.4000/abstractairanica.42195

ISSN : 1961-960X

Éditeur :

CNRS (UMR 7528 Mondes iraniens et indiens), Éditions de l'IFRI

\section{Référence électronique}

Matthieu Chochoy, «Cristelle Baskins. The Bride of Trébizond: Turks and Turkmens on a Florentine Wedding Chest, circa $1460 »$, Abstracta Iranica [En ligne], Volume 34-35-36 | 2017, document 18, mis en ligne le 30 juillet 2017, consulté le 28 septembre 2020. URL : http://journals.openedition.org/ abstractairanica/42195; DOI : https://doi.org/10.4000/abstractairanica.42195

Ce document a été généré automatiquement le 28 septembre 2020.

Tous droits réservés 


\title{
Cristelle Baskins. The Bride of Trébizond: Turks and Turkmens on a Florentine Wedding Chest, circa 1460
}

\author{
Matthieu Chochoy
}

\section{RÉFÉRENCE}

Cristelle Baskins. « The Bride of Trébizond: Turks and Turkmens on a Florentine Wedding Chest, circa 1460 ». Muqarnas, 29, 2012, p. 83-100.

1 À travers cet article, Cristelle Baskins propose une nouvelle analyse de la principale scène peinte décorant un coffre en bois fabriqué à Florence probablement entre 1459 et 1460 et connu sous le nom de " coffre de la conquête de Trébizonde ". Baskins réfute l'idée qu'il s'agirait de la prise de la ville par les Ottomans en 1461, sur l'argument qu'il n'y aurait aucune raison de rappeler une victoire ottomane sur un mobilier destiné à être offert pour un mariage. Par une analyse de l'évolution du contexte géopolitique de la ville, l'A. arrive à la conclusion que cette scène représente au contraire la défaite de Mehmet II face au prince turkmène Uzun Hasan, alors allié de Florence, dans les années 1459-1460.

2 L'originalité de cette lecture repose sur l'interprétation de l'inscription « Tan[b]urlana » [Tamerlan] apposée à côté de l'un des deux personnages assis sur le chariot de l'armée victorieuse. L'A. y voit, à juste titre selon nous, un rappel de la filiation entre la dynastie turkmène et l'empereur timouride destinée à faire rejaillir le prestige de Tamerlan sur Uzun Hasan et à en légitimer le pouvoir. Dès lors, cette conquête de Trébizonde sur les Ottomans s'inscrit dans la continuité de la célèbre victoire d'Ankara qui avait vu la fin de Bayazıt $\mathrm{I}^{\mathrm{er}}$ et la défaite, du moins temporaire, des Ottomans.

La dernière question soulevée par l'A. porte sur l'identification du commanditaire de ce coffre. Sans pouvoir cibler un acteur précis, les recherches de Baskins se tournent 
logiquement vers le milieu marchand, plus facilement averti des jeux d'alliance de Trébizonde et en capacité d'en connaitre rapidement les évolutions.

4 Cet article illustre, s'il en était besoin, combien l'actualité politique de l'Orient était un sujet d'inspiration pour les artistes florentins. Une telle lecture du " coffre de la conquête de Trébizonde » peut dès lors être considérée comme un nouvel indicateur de la vitesse et de la précision de la circulation des savoirs.

\section{AUTEURS}

\section{MATTHIEU CHOCHOY}

École Pratique des Hautes Études 